\title{
Maria na Teologia Simbólica da Patrística
}

Mary in Symbolic Theology of Patristic

Pedro K. Iwashita *

Resumo: Este artigo tem como objetivo falar sobre a presença de Maria na Teologia dos Santos Padres, desenvolvida nos primeiros séculos do cristianismo, em que houve a necessidade de se traduzir a Boa-nova para a cultura helênica principalmente. Embora haja a precedência dos textos do Novo Testamento no que se refere à Maria da história, mas pode-se comprovar a presença de Maria também na vida da Igreja apostólica, testemunhado pelos numerosos textos dos Padres da Igreja, que falaram e escreveram com entusiasmo sobre Maria. Nos primeiros séculos do cristianismo insistiu-se na identidade entre Maria e a Igreja. A Igreja Primitiva via a Igreja em Maria e Maria na Igreja, de maneira que o grande amor pelo mistério da Igreja-Mãe, só se compreende a partir do grande amor que havia pela mãe terrestre do Salvador. Para se falar sobre o papel de Maria, os autores da Patrística usaram paralelismos, entre eles, o paralelismo Maria/Eva e em seguida o paralelismo Maria/Igreja.

Palavras-chave: Patrística; Maria; Símbolo; Paralelismos; Eva.

Abstract: This article aims to discuss the presence of Mary in the theology of the Fathers, developed in the early centuries of Christianity, when there was the need to translate the Good News to the Hellenic culture mainly. While there is precedence of the New Testament in

* Doutor em Teologia pela Universidade de Fribourg, Suiça. Do Programa de Estudos Pós-Graduados em Teologia, da PUC/SP. Líder do Grupo de Pesquisa: Teologia e Espiritualidade. 
relation to the historical Mary, but it can prove the presence of Mary in the life of the apostolic Church, witnessed by the numerous texts of the Church Fathers, who spoke and wrote enthusiastically about Mary. In the early centuries of Christianity insisted on the identity of Mary and the Church. The early church saw the Church in Mary and Mary in the Church, so that the great love for the mystery of the Mother Church can only be understood from the great love it had for the earth mother of the Savior. To talk about the role of Mary, the patristic authors used parallelisms between them, parallelism Mary/Eve and then Mary/Church.

Keywords: Patristic; Mary; Symbol; Parallelisms; Eve.

\section{Introdução}

A Teologia Patrística se desenvolveu nos seis primeiros séculos, período que compreende a geração posterior aos apóstolos até o momento da transição para a teologia medieval. O cristianismo estava com o grande desafio de ter que traduzir a boa-nova para a cultura helênica, mas também é desafiado a se justificar diante dos que se servindo da filosofia grega, viam a fé cristã como sendo inferior e secundário. Neste contexto, os Padres da Igreja respondem a esse desafio, mantendo o fermento evangélico nos aspectos existencial, práxico e intelectivo. No empenho de inculturação, adota-se símbolos e expressões religiosas e utiliza-se categorias dos esquemas mentais de seus interlocutores, para lhes tornar compreensível a boa-nova. Os protagonistas da teologia patrística elaboraram a reflexão de fé com o objetivo pastoral e para isso se serviram com frequência do uso do símbolo. ${ }^{1}$ A presença de Maria na evangelização é destacada pelo Papa Francisco na Exortação Apostólica Evangelii Gaudium: “Juntamente com o Espírito Santo, sempre está Maria no meio do povo. Ela reunia os discípulos para $O$ invocarem (cf. At 1,14), e assim

1 Cf. LIBANIO, J.B.; MURAD, A., Introdução à Teologia. Perfil, Enfoques, Tarefas, pp. 102-104. 
tornou possível a explosão missionária que se deu no Pentecostes. Ela é a Mãe da Igreja evangelizadora e, sem Ela, não podemos compreender cabalmente o espírito da nova evangelização” (EG, 284).

No que toca à Maria da história, é fundamental nos referirmos aos textos do Novo Testamento, principalmente a Paulo, aos Evangelhos Sinóticos e a João. Embora os textos do Novo Testamento sejam bastante sóbrios no que se refere a Maria, mas aquilo que é dito sobre ela é de importância fundamental, e que comprova a presença de Maria primeiramente na vida de Jesus e também na vida da Igreja apostólica, presença essa que continuará no desdobramento da Igreja, testemunhado pelos numerosos textos dos Padres da Igreja, que falaram e escreveram com entusiasmo sobre Maria. ${ }^{2}$ No Novo Testamento se evidencia a íntima união de Maria à vida e à obra de Jesus. Na Patrística ou na Tradição, por sua vez, aprofundou-se sobre a pessoa de Maria, o seu ser, os seus privilégios, a natureza da devoção à sua pessoa, em quem a Igreja vê como sendo a via privilegiada para se chegar a Cristo. ${ }^{3}$

Nos primeiros séculos do cristianismo insistiu-se na identidade entre Maria e Igreja. A Igreja primitiva via a Igreja em Maria e Maria na Igreja. O seu grande amor pelo mistério da Igreja-Mãe, só se compreende a partir do grande amor que havia pela mãe terrestre do Salvador. ${ }^{4}$ Com efeito, na Igreja primitiva, conhecia-se mais claramente e com mais entusiasmo o mistério segundo o qual a palavra de Deus, ao apresentar os traços de Maria Virgem-Mãe, no-la apresentava como a "figura e recapitulação" da Igreja-Mãe. Via-se

2 Uma seleção valiosa de textos patrísticos sobre Maria traz o livro: Texte zur Theologie - Dogmatik, editado por Wolfgang BEINERT, vol. 6: Mariologie, seleção de textos por Franz Courth, Verlag Styria, Graz Wien Köln, 1991. Cf. tb. LAURENTIN, René. Marie Mère du Seigneur. Les beaux textes de deux millénaires, Desclée, Paris, 1984.

3 Cf. DEL GAUDIO, Daniela. Maria de Nazaré. Breve tratado de mariologia. São Paulo: Paulus, 2016, p. 53.

4 Cf. MÜLLER, A., Ecclesia - Maria. Die Einheit Marias und der Kirche, Freiburg/CH, 63, (PG 7, 1074) 
também a vida inteira da Mãe de Deus, da sua concepção imaculada até a sua assunção, como uma só e única prefiguração do ser e do destino da Igreja e da nossa própria vida espiritual. E no seio desta Mãe, que nos deu o Deus Salvador, que começa a história da Igreja; e é na Igreja que se consuma, que se cumpre nossa própria destinação eterna; é nela que o mundo retorna a Deus e é salvo da decadência que a maldição do pecado original introduzira na criação. ${ }^{5}$ Efrém, o Sírio, traduziu essa realidade de maneira profunda, dizendo: "A terra, esta mãe dos corpos humanos, foi maldita. Mas por amor do Corpo da Igreja, que jamais se corrompe, a terra deste Corpo foi abençoada desde o início: a terra da Igreja é, com efeito, o corpo de Maria, na qual ela foi semeada" ${ }^{6}$

Essa imagem patrística de Maria como sendo a terra da Igreja, o solo no qual está plantada, e onde estende também as suas raízes, nos conduz a outra ideia patrística de grande importância, a saber, Maria como tipo (typos) ou arquétipo (arquetypos) da Igreja. Segundo Otto Semmelroth, ${ }^{7}$ Maria foi sempre vista na tradição teológica católica como a imagem primordial, arquétipo da Igreja (“Urbild der Kirche”).

\section{A paralelismo Maria/Eva}

Entre os antigos autores da Patrística, a paralelismo Maria/ Eva é o mais antigo de todos, ${ }^{8}$ muito mais antigo que o de Maria/ Igreja que, embora já presente no Novo Testamento, foi posterior na

Ibidem, p. 12-13.

6 “Já que os corpos pecaram, eles mesmos morrem e a terra, que é a sua mãe, foi amaldiçoada, da mesma forma, por causa da Igreja que também é um corpo, mas um corpo que não se corrompe, a terra foi abençoada logo de início; o corpo de Maria, eis a terra da Igreja, na qual ela foi gerada”. Efrém Sírio, Ev. conc. exp., in MÖSINGER, G. Evangelii concordantis expositio facta a S. Ephraemo doctore Syro..., 48-49, apud MÜLLER, Alois, op. cit., 151.

7 Cf. SEMMELROTH, 1965, Marie, archétype de 1'Église, Paris. Cf. tb,. MD 4.

8 Cf. POZO, Candido. María en la obra de la salvación. Madri, 32. Cf. tb. MD 11. 
tradição e na reflexão teológica da Igreja..$^{9}$ O paralelismo Maria/ Eva constitui, na realidade, importante teologúmeno, cuja primeira apresentação nos é dada pelo apologista Justino (165 d.C.), tendo assim inaugurado, ocasionalmente, a temática que, mais tarde, através de santo Irineu (202 d.C.) recebeu um estatuto teológico. ${ }^{10}$

A importância desse tema é dupla, a saber: primeiramente como uma etapa do desenvolvimento da doutrina marial, e em seguida, o que é mais importante ainda, a integração de Maria na história da salvação. ${ }^{11}$

No seu diálogo com o judeu Trifão, Justino aplica o Sl 21 a Cristo, afirmando que ele é Filho de Deus antes de toda a Criação, e que "se é por intermédio de uma virgem que ele se fez homem, foi no desejo de que, pela mesma via em que a desobediência, oriunda da serpente, teve o seu princípio, encontre igualmente a solução. Com efeito, Eva, sendo virgem e incorrupta, deu luz à desobediência e à morte pela palavra saída da boca da serpente. Maria, a Virgem, ao contrário, concebeu fé e alegria, no momento em que o anjo Gabriel lhe deu a boa notícia de que o Espírito do Senhor viria sobre ela e o poder do Altíssimo a cobriria com sua sombra, de modo que o Santo, que seria dado à luz por ela, seria Filho de Deus, respondeu: 'faça-se em mim segundo tua palavra'. E dela nasceu aquele sobre quem, como temos demonstrado, tantas passagens das Escrituras falam, através do qual Deus destrói a serpente, os anjos e os homens

$9 \quad$ Ibidem, 32.

10 Cf. MÜLLER, Alois. Ecclesia - Maria. Die Einheit Marias und der Kirche. $2^{\text {a }}$ ed. Freiburg/CH, 48; LAURENTIN, René. Court traité sur la Vierge Marie. Paris, 42.

11 Cf. LAURENTIN, René. Court traité sur la Vierge Marie. Paris, 43 Essa comparação entre Maria e Eva revela uma característica muito interessante da maneira de pensar dos Padres. Id., 43: "O pensamento dos Padres, mais intuitivo que dedutivo, mais simbólico que lógico, evolui não em forma de silogismos, mas pela confrontação de teses e símbolos carregados de verdade. Discernem entre Eva e Maria um paralelo e um contraste. Paralelo de situação, pois nos dois casos, uma mulher, uma virgem fez um ato moral que implica a salvação de toda a humanidade. Contraste de engajamento, pois Eva desafia Deus e desobedece, enquanto Maria acredita e obedece. O resultado é de um lado o pecado e a morte, de outro lado a salvação e a vida”. 
que se assemelham a ela; libertando, porém, da morte os que se convertem das más obras e nele creem”."12

Segundo o contexto destas palavras de Justino, não se trata primeiramente de explicação da relação entre Maria e Eva, e sim da aplicação do S1 21 a Cristo. ${ }^{13}$ Mas na vitalidade do seu pensamento, as ideias lhe vêm uma atrás das outras, sem ordem rígida, e nessa cascata de ideias um ensinamento sobre Maria toma forma, o que, pelo visto, lhe é familiar. Nesse ensinamento é desenvolvida a ideia da recirculação, a saber, do fato de que pelo mesmo caminho que a desobediência começou, foi ela novamente desfeita, remetendo-nos assim a Rm 5,19, embora se trate ali do paralelo Adão/Cristo. Aqui, embora o paralelismo entre Maria e Eva não seja muito feliz, o seu pensamento é claro: a virgem Eva e a Virgem Maria se encontram uma diante da outra. Enquanto uma produz a desobediência pela palavra do anjo mau, a outra, pela palavra do anjo bom produz a obediência na fé e na alegria; Eva acolhe então a palavra do diabo, e Maria concebe o Logos de Deus. ${ }^{14}$

A esse tema esboçado por Justino, santo Irineu de Lion procurou dar relevo impressionante, pois para ele o paralelo Maria/Eva é peça integrante de sua teologia da salvação, na base da qual se encontra a ideia de que o plano salvífico de Deus não é um remendo da primeira obra, mas uma retomada pelo princípio, uma regeneração pela cabeça, enfim, a recapitulação em Cristo. Aparece também a mesma ideia da recirculação (recirculatio): o Cristo retoma Adão; a cruz, a árvore da queda, e nesse conjunto, Maria que retoma Eva, ocupa lugar de

12 Dial. C. Tryph. 100; (PG 6, 712).

13 Cf. MÜLLER, Alois. Ecclesia - Maria. Die Einheit Marias und der Kirche. $2^{\text {a }}$ ed. Freiburg/CH, 49.

14 Ibidem, 49-50. Essa confrontação Eva-Maria é vista como uma simples extensão da antítese Adão-Cristo. A questão que se propõe é a de saber se JUSTINO faz intencionalmente referência ao Protoevangelho e se é dali que ele tira o paralelo Eva/Maria. Uma coisa, no entanto, parece certa, a saber, JUSTINO vê no Filho da Virgem Maria, que destrói o demônio e seu sangue, a realização do Protoevangelho. Id., 50-51. 
primeiro plano. ${ }^{15} \mathrm{O}$ princípio fundamental é o desenvolvimento, dirigido por Deus, de toda a história do mundo para a unificação da criação com o Criador, de acordo como se consumou em Cristo, ${ }^{16} 0$ novo Adão, o perfeito, a cabeça da humanidade, por ele e nele regenerada. Por sua encarnação, o Cristo recapitula em si a longa série de homens que estavam à procura da salvação, restaurando neles a imagem e a semelhança com o Pai. ${ }^{17}$ Nesta monumental epopeia da salvação, da restauração, da recapitulação, operada pelo Filho de Deus, Irineu apresenta o paralelo entre as duas virgens, Eva e Maria.

Ao dizer que "o inimigo não teria sido vencido convenientemente se seu vencedor não fosse homem nascido de mulher, uma vez que no começo foi através da mulher que ele ganhou domínio sobre 0 homem, tornando-se seu inimigo", ${ }^{18}$ Irineu apresenta um pensamento que já se esboçava em Justino, a saber, "per feminam mors, per feminam vita”, através da mulher veio a morte, através da mulher veio a vida. Nesse sentido Maria é vista como a recapitulação da "mulher" Eva, assim como Cristo é a da humanidade ou de Adão, ${ }^{19}$ o que é dito de maneira mais expressiva ainda no seguinte texto: "E como aquela... desobediente se tornou causa de morte para si e para o gênero humano, assim Maria, obediente, se tornou para si e para todo o gênero humano a causa da salvação... Assim as amarras da Eva desobediente foram desatadas através da obediência de Maria, pois o que a Eva virgem ligou pela incredulidade, a Virgem Maria desligou pela fé”. ${ }^{20}$

15 Cf. LAURENTIN, René. Court traité sur la Vierge Marie. Paris, 43. DE FIORES, in: NDM, 1387.

16 Cf. MÜLLER, A. Ecclesia - Maria. Die Einheit Marias und der Kirche, Freiburg/CH, 28; Adv. haer. 4, 20; (PG 7, 1034B).

17 Cf. DE FIORES, in NDM, 1387.

18 Cf. PG 7,1179 AB: "Pois o inimigo não teria sido vencido de uma maneira justa (adequada), se não viesse da mulher aquele que venceu, pois por uma mulher o homem foi vencido, no início, fazendo-se a si mesmo inimigo para o homem”.

19 Cf. PG 7, 964B.

20 Cf. PG 7, 959-960. 
Irineu apresenta o paralelismo entre Maria e Eva nos seguintes elementos:

1. Eva abriu à Serpente o caminho em direção da humanidade trazendo assim a morte - Maria deu à luz Cristo, que esmagou a cabeça da serpente, e trouxe assim a vida.

2. A atitude interior de Eva foi a incredulidade contra Deus, donde a sua desobediência - a atitude interior de Maria foi de fé, donde a sua obediência.

3. No momento da queda, Eva tinha marido, mas era virgem Maria tinha igualmente marido e foi sempre virgem. ${ }^{21}$

A ideia que atravessa todos esses argumentos é a da recapitulação: assim como a condenação, também a salvação da humanidade veio pelo mesmo caminho, mas desta vez pela obediência da mulher que deu à luz o Salvador. Eva é ainda mãe da vida (Gn 3,20), e mãe da morte (PG 7, 1179AB). O paralelo Maria/Eva compensa assim o aspecto luminoso de Maria, e possibilita a polaridade do arquétipo nela.

O que a reflexão de santo Irineu revela é que Maria, recapitulando Eva, a elevou, a redimiu da maldição primordial. A ideia de redenção é usada aqui com precauções, mas é, no entanto, significativa do ponto de vista psicológico, pois, em Maria, Eva não foi recalcada, e sim elevada e conduzida à mutação, ao positivo. No círculo interior do arquétipo, é fundamental que o aspecto negativo se transforme em positivo, ou que contribua para a mutação positiva do feminino. Esse aspecto de intercessão, de mediação de Maria em relação a Eva, a “mãe de todos os viventes”, santo Irineu o exprimiu pelo termo "advogada”, "defensora” (Advocata). ${ }^{22} 0$ título evoca, evidentemente, no contexto do texto, um tema distinto, a saber, o de Maria que obedece,

21 Cf. MÜLLER, Alois. Ecclesia - Maria. Die Einheit Marias und der Kirche. Freiburg/ $\mathrm{CH}, 62$.

22 Cf. PG 7,1175B: "E ainda que aquela desobedeceu a Deus, esta achou por bem obcdecer a Deus, para que a virgem Maria fosse a advogada da virgem Eva”. 
em contraposição a Eva que desobedece. Não se trata de intercessão no sentido próprio da palavra, ou que Maria tenha feito valer alguns méritos a favor de Eva. Maria, fazendo o contrário do que fez Eva, destruiu deste modo a sua obra, e conseguiu retificar as funestas consequências da desobediência de Eva. A alusão é simplesmente à cena da Anunciação, onde o "sim" de Maria possibilitou a vinda do Cristo e, com ele, da salvação. A obediência de Maria pelo seu “sim” destruiu a ação perniciosa de Eva. ${ }^{23}$ Embora a redenção seja obra única de Cristo, contudo no conjunto do mistério salvífico cada elemento que constitui o todo tem o seu significado soteriológico, emanado, é claro, da única redenção operada por Cristo. Maria tem pois, nesse sentido, um significado soteriológico em relação a Eva, que era esboço antropológico da mulher. Maria é a restauração e aperfeiçoamento desse projeto que havia falido. ${ }^{24}$

O paralelismo Eva-Maria, em Justino e Irineu, representa, em certo sentido, um prelúdio da denominação de Maria como a "Nova Eva”, título esse que, na verdade, foi o fundo implícito, não formulado da antítese Eva-Maria. ${ }^{25}$ Com efeito, na continuação da evolução teológica, "lenta e progressivamente, se reconhecerão, em Maria, todos os aspectos do papel de Eva. Desde 377, Epifânio vê nela a 'Mãe dos viventes', segundo a fórmula de Gn 3,20. E é somente durante a segunda metade do séc. XIII que será posto à luz o último traço do paralelo, a saber, Maria, 'auxiliar semelhante' do novo Adão, segundo a fórmula de Gn 2,18” ${ }^{26}$

23 Cf. POZO, Candido. María en la obra de la salvación. Madri, 35-36; cf. tb. ALDAMA, J. A. Maria en la Patrística de lso siglos I y II. Madri, 1970, 287ss.

24 Cf. LAURENTIN, 1985, in NDM, 1020.

25 Cf. POZO, C. op. cit., 32-33. Interessante é constatar que originalmente a denominação "Nova Eva" não foi criada para Maria, e sim para a mulher de Jó, que o instigou para o pecado. Cf. LAURENTIN, 1985, in NDM, 1020; S. AGOSTINHO, De urbis excidio 3; Pl 40, 719 .

26 LAURENTIN, René. Court traité sur la Vierge Marie. Paris, 44. 
Um dado importante que pudemos verificar nesse estudo, é o fato de que Maria e Eva não se excluem. Maria, como figura luminosa, e Eva, à semelhança de Ísis, sendo figura ambivalente, enquanto mãe da vida e da morte, colocada uma frente à outra, representam, através do paralelo e da antítese, a polaridade necessária do arquétipo, que se torna mais claro ainda no paralelo Maria e Igreja.

\section{2. o paralelismo Maria/Igreja}

Eva era um esboço antropológico da mulher, e Maria, do mesmo modo como a Igreja, é a restauração e a perfeição do projeto que Eva, como a primeira mulher, havia feito fracassar. Os contrastes Eva-Maria e Eva-Igreja fizeram caminho com os Padres, e desembocaram numa aproximação toda feita de harmonias positivas entre Maria e a Igreja. ${ }^{27}$ Segundo Santo Irineu, a passagem em direção do paralelo Maria/Igreja está no fato de que, para ele, Maria é a segunda Eva, a causa da salvação de todo o gênero humano, através do nascimento de Cristo. Nesse sentido Maria, como a segunda Eva, não é oposta diretamente à primeira Eva, e sim ao segundo Adão, que é Jesus Cristo. ${ }^{28}$

Nos primeiros séculos do cristianismo insistiu-se na identidade entre Maria e Igreja. A Igreja primitiva via a Igreja em Maria e Maria na Igreja. O seu grande amor pelo mistério da Igreja-Mãe, só se compreende a partir do grande amor que havia pela mãe terrestre do Salvador. ${ }^{29}$ Com efeito, na Igreja primitiva, conhecia-se mais claramente e com mais entusiasmo o mistério segundo o qual a palavra de Deus, ao apresentar os traços de Maria Virgem-Mãe, no-la apresentava como a "figura e recapitulação" da Igreja-Mãe. Via-se também a vida inteira da Mãe de Deus, da sua concepção imaculada

\footnotetext{
27 Ibidem, 44.

28 Cf. MÜLLER, Alois. Ecclesia - Maria. Die Einheit Marias und der Kirche. Freiburg/ $\mathrm{CH}$, 63. (PG 7,1074).

29 Cf. ibidem, MÜLLER, Alois, op. cit., 63, (PG 7,1074).
} 
até a sua assunção, como uma só e única prefiguração do ser e do destino da Igreja e da nossa própria vida espiritual. E no seio desta Mãe, que nos deu o Deus Salvador, que começa a história da Igreja; e é na Igreja que se consuma, que se cumpre nossa própria destinação eterna; é nela que o mundo retorna a Deus e é salvo da decadência que a maldição do pecado original introduzira na criação. ${ }^{30}$ Efrém, o Sírio, traduziu essa realidade de maneira profunda, dizendo: "A terra, esta mãe dos corpos humanos, foi maldita. Mas por amor do Corpo da Igreja, que jamais se corrompe, a terra deste Corpo foi abençoada desde o início: a terra da Igreja é, com efeito, o corpo de Maria, na qual ela foi semeada". ${ }^{31}$

Essa imagem patrística de Maria como sendo a terra da Igreja, o solo no qual está plantada, e onde estende também as suas raízes, nos conduz a outra ideia patrística de grande importância, a saber, Maria como tipo (typos) ou arquétipo (arquetypos) da Igreja. Segundo Otto Semmelroth, ${ }^{32}$ Maria foi sempre vista na tradição teológica católica como a imagem primordial, arquétipo da Igreja ("Urbild der Kirche").

Aqui o termo "arquétipo" não é usado diretamente no sentido junguiano. ${ }^{33}$ Mas como C. G. Jung deduziu a noção a partir de Dionísio Areopagita, ${ }^{34}$ e sobretudo de outro texto de santo Agostinho, ${ }^{35}$

30 Ibidem, 12-13.

31 “Já que os corpos pecaram, eles mesmos morrem e a terra, que é a sua mãe, foi amaldiçoada, da mesma forma, por causa da Igreja que também é um corpo, mas um corpo que não se corrompe, a terra foi abençoada logo de início; o corpo de Maria, eis a terra da Igreja, na qual ela foi gerada”. Efrém Sírio, Ev. conc. exp., in MÖSINGER, G. Evangelii concordantis expositio facta a S. Ephraemo doctore Syro..., 48-49, apud Müller, Alois, op. cit., 151.

Cf. SEMMELROTH, 1965, Marie, archétype de 1'Église, Paris. Cf. tb,. MD 4.

Cf. JACOBI, J. Die Psychologie von C.G.Jung. Eine Eine Einführung in das Gesamtwerk. Frankfurt a. M., 1982, 47-56; JUNG, C.G., GW 6, 451-454.

34 Cf. "De divinis nominibus", cap. 2, § 6: "e diz o santo Padre, quando explica isso, que aquilo que é dito consolida (ou confirma) mais ainda que isso é um sinal, mas uma variedade que confirma: de uma única forma original fez diferentes imagens ou cópias”, cit. por JACOBI, J. Die Psychologie von C.G.Jung. Eine Eine Einführung in das Gesamtwerk. Frankfurt a. M., 1982, 161, n. 71.

35 Cf. “Liber de divers. Quaest” XLVI, §2: “Pois as ideias são como que as formas principais (moldes primitivos), ou então os conceitos estáveis e imutáveis das coisas, os 
a ideia no fundo se aproxima com a utilização feita por Semmelroth do termo "arquétipo", que ele emprega sem fazer referência nenhuma a C. G. Jung, mas antes ao emprego do termo typos no Novo Testamento (Jo 20,25; At 7,43; Rm 6,17; 5,14; 1Tm 4,12), e nos textos patrísticos, especialmente na apresentação da ideia de Maria como tipo da Igreja. ${ }^{36}$

Se o paralelo Maria/Eva não foi para santo Irineu simples artifício literário e nem improvisação gratuita, mas peça integrante de sua teologia da salvação; ${ }^{37}$ a mesma importância tinha para ele, o paralelo Maria/Igreja. Segundo ele, entre Maria e a Igreja existe uma relação de identidade, que toca de perto a identidade de Cristo com os seus membros, cuja realidade é muito mais importante do que aquilo que a palavra "mística" nos permite imaginar ou supor. ${ }^{38} \mathrm{O}$ Vaticano II retomou, na Lumen Gentium, a ideia patrística de Maria como tipo da Igreja, procurando mostrar assim a identidade profunda existente entre elas: "Em virtude da graça da divina maternidade e da missão pela qual está unida com seu Filho Redentor, e em virtude de suas singulares graças e funções, a Bem-aventurada Virgem está

quais agora são formados, e por isso são eternos e se conservam sempre no mesmo estado, estão contidos na divina inteligência. E já que as ideias não perecem, pode-se dizer que de acordo com elas tudo é formado, o que, algum dia, talvez venha à luz do mundo e se acabe, pois tudo o que nasce morre. A um ser criado não é dado vê-las (ideias), a não ser a um dotado de inteligência.” cit. por JACOBI 1982, 161, n. 71. Foi sobretudo a expressão "ideae principales", que segundo o seu sentido se deixa traduzir por "arquétipo", que motivou C.G. JUNG na escolha do termo. Com "primitivae formae” "ideae principales", quis C.G.JUNG designar o arquétipo, como sendo a imagem originária ou primordial, com caráter coletivo e comum a todos os tempos e povos. Cf. GW 6, 453 (762-764).

36 Cf. SEMMELROTH, O. Marie, archétype de 1'Église. Paris, 38-47. Em Santo Irineu, por exemplo, Maria aparece frequentemente como modelo ou tipo da Igreja. Cf. MÜLLER, Alois. Ecclesia - Maria. Die Einheit Marias und der Kirche. Freiburg/CH, 75: "Muitas vezes Maria e chamada de 'modelo' ou ‘tipo' da Igreja”. Cf. LAURENTIN, René. Court traité sur la Vierge Marie. 5. ed. Paris, 43.

Cf. MÜLLER, Alois. Ecclesia - Maria. Die Einheit Marias und der Kirche. Freiburg/ CH, 75. P. GÄCHTER caracteriza a nossa unidade com Cristo com a expressão: "übernatürlich-physische Verbindung”. GÄCHTER P: "Unsere Einheit mit Christus nach dem hl. lrenäus”, in Zeitschr. f. kath. Theol 58 (1934),503-532, cit. por MÜLLER, Alois, op. cit., 54. 
também intimamente relacionada com a Igreja. Já santo Ambrósio ensinava que a Mãe de Deus é o tipo da Igreja na ordem da fé, da caridade e da perfeita união do Cristo. No mistério da Igreja - pois também a Igreja é com razão chamada mãe e virgem - a Bem-aventurada Virgem Maria ocupa lugar eminente e singular como modelo de virgem e de mãe". ${ }^{39}$

Embora Maria transcenda a Igreja ${ }^{40}$ as duas realidades se iluminam e se esclarecem mutuamente. No conceito de Maria como arquétipo da Igreja, temos a explicação de como Maria representa a essência mais íntima da Igreja. Como figura personificada da Igreja, a faz próxima dos homens, pois nela a Igreja una e múltipla aparece resumida como em germe, para se desdobrar na imensidade do espaço e do tempo, da mesma maneira que o título de um livro contém em germe todo o seu desenvolvimento, e é evidente que esse arquétipo deva conter uma espécie de programa para a atitude moral dos membros da Igreja. De outro lado, a Igreja ilumina a figura de Maria, pois se ela estiver separada desse conjunto ontológico dificilmente a personalidade de Maria, cuja vida nos é tão pouco conhecida em seus detalhes concretos, poderia ser proposta como modelo de vida cristã. ${ }^{41}$

Podemos dizer que o conceito de Maria, como arquétipo da Igreja, apresenta pontos comuns em relação ao conceito psicológico de arquétipo, o que se poderia resumir nos seguintes elementos: o aspecto de imagem primordial; o aspecto de eficácia dessa imagem, que personifica ou representa um conteúdo espiritual. Nesse sentido os Padres, influenciados pelo neoplatonismo, aplicavam livremente a relação arquétipo-imagem à realidade sobrenatural da graça, o que podiam fazer com todo o direito, porque a concepção neoplatônica

39 LG 63.

40 As reflexões aqui desenvolvidas sobre a relação entre Maria e a Igreja, não nos devem conduzir à redução eclesiológica de Maria, pois ela é uma realidade complexa que transcende a Igreja.

${ }^{41}$ Cf. SEMmelroth, O. Marie, archétype de 1'Église. Paris, 1965, 31. 
da imagem, apresentada filosoficamente, se realizou plenamente no domínio da realidade da graça sobrenatural, de modo que existe entre o arquétipo e a imagem contato real e certa relação causal. Transportado para a realidade mariológica, verifica-se então a representação de uma ideia, de um conteúdo espiritual, por uma figura concreta, que é Maria, e que age sobre o homem como motivo eficaz. Nessa figura concreta, a Igreja descobre seus próprios traços essenciais, de modo que a semelhança entre a figura de Maria e da Igreja é a consequência de uma relação interna de natureza real e objetiva. Os traços que tornam a imagem semelhante ao arquétipo decorrem, de alguma maneira, do arquétipo mesmo.

Enfim, o arquétipo apresenta também o caráter de modelo moral em relação à imagem, porque Maria, que representa aqui o arquétipo, é pessoa viva. Sem dúvida, a imagem é um conjunto que, como tal, não possui personalidade própria, mas que, no entanto, está articulada em individualidades que, apesar de toda a realidade da unidade do corpo místico de Cristo, não perdem sua personalidade. É por isso que o arquétipo deve ser para os membros da imagem, modelo moral em relação à sua atitude pessoal e à ação que a precede. ${ }^{42}$

Esses elementos nos mostraram, contudo, uma diferença entre a ideia de Maria como arquétipo, e o arquétipo no seu sentido psicológico. No caso de Maria, trata-se de personalidade histórica, viva, enquanto o arquétipo em si representa uma realidade de natureza psíquica, potencial, se bem que também real e eficaz. Junto com a noção de Maria, como arquétipo da Igreja, seria preciso lembrar também, segundo J. Baumgartner, a noção de Maria como ícone da Igreja. Essa reflexão nos permite compreender a identidade que existe entre Maria e a Igreja.

42 Cf. ibidem, 28-31 


\section{Jesus Cristo como figura do herói que vence a morte}

Na mitologia o filho da Grande Mãe aparece como filho divino, em quem se unem os poderes psíquicos “inferiores” inconscientes, com os "superiores", conscientes, constituindo a imagem primordial do homem psíquico total. Aqui aparece a função redentora e salvadora do filho divino. O filho divino traça o caminho pelo qual o homem deve ser libertado, vale saber, promovendo a separação do maternal primordial, através de provações e sofrimentos, e a maior parte das vezes através da transformação na morte, para uma vida nova. Como filho da Grande Mãe, o filho divino representa a unidade ainda natural e inconsciente da existência psíquica. A descida e o renascimento do filho, celebrados nos mitos, apontam como meta a totalidade consciente, conseguida através de sofrimentos. ${ }^{43}$ Em todo esse processo vital, os filhos da Grande Mãe correm o perigo de falhar, pois, se a consciência ou o Eu não é suficientemente forte, acaba sendo tragado pelo inconsciente. 0 tema do herói que morre e ressuscita, simbolizado poderosamente no sol que é tragado pela noite e que ressuscita, age eficazmente na psique humana. ${ }^{44}$

Os Padres compreenderam muito bem a importância do símbolo solar que, além disso, exerceu papel decisivo na religião do Antigo Egito. Não existe outro símbolo maior de Cristo, na criação, do que o sol que se levanta de manhã, que traz ao universo a luz que aquece e que desperta a vida. ${ }^{45}$

O profeta Malaquias já anunciava: "Para vós, os que temeis o meu nome, nascerá (o Messias) o sol da justiça e a salvação estará sob as suas asas (ou raios); vós saireis então, e saltareis (de alegria)

43 Cf. KASSEL, M., “Weibliche Aspekte im lukanischen Kindheitsevangelium”, in Diakonia, nov. 1984, 392.

44 Cf. JUNG, C.G. GW 5, (310).

45 Cf. DÖLGER, Franz Josef. Die Sonne der Gerechtigkeit und der Schawarze. Münster 1979; id., Sol Salutis, Münster 1972. 
como novilhos de manada” ( $\mathrm{Ml} 4$,2). Cristo dissera de si mesmo: "Eu sou a luz do mundo" (Jo 8,12).

A salvação foi prometida por Deus como luz. Enquanto o povo da antiga aliança ia pelo seu caminho escuro e cheio de sofrimentos, ansiava pelo amanhecer da salvação. Isaías proclamava então: “Este povo, que andava nas trevas, viu uma grande luz; aos que habitavam na região da sombra da morte nasceu-lhes o dia” (Is 9,2).

Cristo aparece como o sol da justiça e da salvação. Compreende-se melhor essa imagem, desde que festejamos a noite pascal e velamos pelo aparecimento pascal do Senhor, que põe fim à noite da morte e introduz o novo dia. A vigília pascal é a essência de toda a oração cristã, que é sempre oração de espera pela manifestação do Senhor. É por isso que a Igreja antiga, na sua oração, voltava-se para o leste, em direção do nascer do sol, assim como aquele monge do deserto que, ao pôr-do-sol, se dirigia com os braços abertos levantados para o leste, velava a noite toda em oração, até que aurora se manifestasse e, logo em seguida, os raios do sol que vinha se levantando viessem de encontro ao seu rosto. ${ }^{46}$

Na liturgia católica da noite pascal encontramos assim pensamentos vivos sobre o sol noturno e o levantar do sol. Nunca um drama cúltico conseguiu exprimir tão bem as oposições trevas e luz, noite e sol, através de palavras e gestos, como o mistério pascal da liturgia romana. Diante da proclamação "Lumen Christi, Deo Gratias", a nova luz é introduzida na igreja ainda escura, sob o "Exultet”, e a canção de louvor pelo círio pascal, símbolo do Cristo, o sol daquela noite, o verdadeiro "Sol invictus", que sobe vitorioso das profundidades do reino dos mortos. ${ }^{47}$

46 Cf. RAHNER, Hugo. Griechische Mythen in christlicher Deutung. Zurique 1966; cf. tb. Apophthegmata, Arsenius 30(PG 65, 97C); EBEL, B., "Aufgang der Kirche. Eine Verkündigung über Maria in der Bildersprache der Väter”, in BOGLER, Th. (Org.): Maria in Liturgie und Lehrwort, Maria Laach, 1954.

47 Cf. RAHNER, H., op. cit., 119; EBEL, B., op. cit. 25-26; SANTO AGOSTINHO, Sermo 190,1; PG 38, 1007; SERMO 287, 4; PL 38, 1302. 


\section{Maria como a nova aurora que anuncia o Salvador}

Se Cristo é o sol da justiça e da Salvação, Maria é a aurora da Nova Aliança. Segundo Honório de Autun, "ela é aquela que avançando da massa pecadora, como a aurora, se levanta das trevas, da qual o sol da justiça aparece iluminando os que jazem nas trevas e nas sobras da morte" ${ }^{48}$ Se Maria é a aurora que anuncia o sol da justiça, a luz desse mesmo sol se anuncia nela. Na natureza o dia não substitui de repente a noite, e o sol não sai de um só golpe da noite, mas envia antecipadamente a luz para a aurora ${ }^{49}$ assim em Maria, como a aurora da salvação, a face do Cristo sol da justiça é refletida antecipadamente, na claridade da aurora.

$\mathrm{Na}$ rica linguagem simbólica dos Padres, Maria é também a terra, de onde nasce o Cristo, o sol da justiça e da salvação. Santo Agostinho escrevia: "A verdade surgiu da terra, porque Cristo nasceu da Virgem" ${ }^{50}$

Se Maria é a terra que deu à luz Cristo, ela é também, como dissemos, a aurora que anuncia a chegada desse sol da salvação. Rupert von Deutz escrevia: "Quando nasceste, ó bem-aventurada Virgem, nos apareceu a verdadeira aurora, como precursora do dia perpétuo; pois assim como a aurora anuncia o final da noite que passou e o começo do novo dia, do mesmo modo o teu nascimento vindo da semente de Abraão, claridade vinda da árvore de Davi, aos quais coube com o juramento de Deus a promessa da bênção - foi o final das dores e o começo da consolação, o fim da tristeza e a fonte da alegria" ${ }^{11} \mathrm{Na}$ festa da Natividade de Maria canta-se com alegria: “O teu nascimento, Virgem Mãe de Deus, anunciou a alegria para o mundo todo. De ti é que nasceu o sol da justiça, Cristo, nosso Deus,

\footnotetext{
48 Sigill. 6 (PL 172, 512A).

49 Cf. EBEL, B., op. cit., 27.

50 SANTO AGOSTINHO, Sermones 189 (PL 38, 1006).

51 RUPERT VON DEUTZ, Cant. 6 (PL 168, 939).
} 
que, anulando a palavra da maldição, nos deu a palavra de bênção; desconcertando a morte, nos deu a vida eterna". ${ }^{52}$

Transcrevendo toda essa simbologia para o contexto mítico e arquetípico, dir-se-ia que Cristo, o “Sol invictus”, é a corporificação da figura mítica do herói que, tendo vencido a dura prova, sai vitorioso das entranhas da morte, do ventre da Grande Mãe terra, pela sua ressurreição. Essa vitória nos é simbolizada cada manhã pelo sol que se levanta da terra ou do mar, irradiando a vida em infinita profusão. A Grande Mãe Maria não retém prisioneiro o seu Filho, ${ }^{53}$ mas ela é a terra ou o mar, que oferece ao mundo o Salvador, seu Filho divino. Ela é a aurora formosa que anuncia cada manhã o nascimento do sol que, tendo atravessado as trevas da noite, oferece luz e vida. É toda outra perspectiva que não a do mito e do culto de Iemanjá, que, como a Grande Mãe devoradora, arrasta seus filhos para as profundidades abissais do mar. Delineia-se então aqui toda uma dimensão soteriológica em Maria como figura da Grande Mãe junto com o seu Filho divino.

\section{Pelo batismo participamos na vitória do Cristo}

Pelo batismo, participamos no mistério da morte e ressurreição de Cristo, simbolizado, como vimos até agora, pelo sol que morre e renasce: "não sabeis que todos os que fomos batizados em Cristo Jesus, é na sua morte que fomos batizados? Pois pelo batismo nós fomos sepultados com ele na morte para que, como Cristo foi ressuscitado dentre os mortos pela glória do Pai, assim também nós vivamos vida nova" (Rm 6,3-4; cf. Ef 5,8).

Em Cristo temos, pois, a esperança de que as noites, que temos de atravessar, terminarão sempre pelo raiar do dia, pelo nascimento do sol e quando tivermos de atravessar a noite decisiva na morte,

52 Breviar. Monast., In Nat. B.M.V., in 2 Vesp. Ant. ad Mafn., cit. por EBEL, B., op. cit., 28.

53 Cf. PAULO VI, Marialis Cultus, 37. 
nele temos então a esperança definitiva de que raiará o dia eterno. Esse fato é de significado soteriológico fundamental. O sol simboliza a consciência que em si é comparada a uma luzinha de vela, mas que aspira a ser como o sol; essa consciência é oposta à escuridão incomensurável do inconsciente. Se a luzinha da consciência se apagar, tragada pelo oceano primordial do inconsciente, então será a loucura, a esquizofrenia, o crime ou o desvio moral do homem. Mas Cristo é o "Sol invictus", o timoneiro do barco da salvação (Igreja), que nos conduz com segurança ao porto da salvação. Nele, mesmo a morte, que é uma descida à inconsciência completa, é garantida pelo raiar de um novo dia.

Aqui é preciso distinguir a dupla dimensão da consciência, a saber, a psíquica e a moral. Cristo é a luz da consciência moral, favorecendo por acréscimo a saúde da consciência psíquica. Ele não veio nos livrar somente da loucura e da inconsciência, mas como a luz da consciência moral, também do crime e do pecado, favorecendo igualmente a saúde e o equilíbrio da consciência psíquica.

\section{A presença de Maria na barca da salvação}

A existência terrestre da Igreja é comparável a uma viagem em navio, porque ela é fundamentalmente do além, sempre em viagem, em direção a uma pátria ainda não alcançada; porque essa viagem vai sobre o "mar do mundo", portanto sobre um elemento hostil e perigoso para o navio, que é pequeno e de madeira, mas que, justamente por isso, pode desafiar a obstinação do mar. Atrás desse mundo de símbolos da dogmática patrística se esconde uma eclesiologia dialética com seus pares de opostos: a Igreja é, de um lado, segura de sua salvação, e, no entanto, ainda sujeita ao perigo de perdê-la; certa de alcançar o porto, mas não chegou ainda ao ponto final; um pequeno pedaço de madeira, do lenho da cruz, sobre esse mar terrível do mundo dominado pelo demônio, mas, justamente nessa sua insignificância, é segura de sua vitória. Isto porque ela é 
construída com o madeiro da cruz, o pequeno lenho a que os homens confiam suas vidas, e com isso é representada simbolicamente a sua natureza profunda, pois a Igreja é a continuação histórica e a perfeição daquela vitória a qual o Cristo sobre o madeiro conquistou sobre os "príncipes deste mundo". Madeira e mundo, navio e mar, Cristo e Satã, são polaridades nas quais se encontram os interesses teológicos, com os quais esta simbólica patrística é carregada. ${ }^{54}$

No mar da vida, singra então a pequena barca de madeira, tendo como mastro a cruz da salvação, e por grande timoneiro, Jesus Cristo. Na sua viagem rumo ao porto da eternidade, o cristão se vê diante do perigo mortal da escolha entre a fé e incredulidade, simbolizado pela figura feminina das perigosas sereias. ${ }^{55}$ Mas felizmente, no barco, que simboliza a Igreja, se encontra uma figura feminina especial, a saber, a Virgem Maria, a mãe do timoneiro Jesus Cristo. No livro de orações do assim chamado “Oktoichos” da Igreja ortodoxa católica, encontra-se a seguinte invocação: "Santíssima Senhora, que destes à luz, aos mortais, o Senhor como timoneiro, acalmai as ondas terríveis e selvagens de minhas paixões, e dai a paz ao meu coração". ${ }^{56}$

Como mãe do timoneiro da barca da Igreja, a nova criação, Maria representa papel importante na obra da redenção. No pensamento patrístico, ela é, segundo a fórmula de Gn 2,18, a auxiliar corresponde do Novo Adão. ${ }^{57}$ Se Maria, a segunda Eva, é auxiliar, ajudante de Cristo, Cristo e Maria formam o par da redenção, pois fomos salvos pelo Cristo e sua auxiliar e mãe Maria. Essa especial participação de Maria na obra da redenção, na obra da nova criação, vem do fato de sua maternidade divina, que não foi ato simplesmente físico, mas

\footnotetext{
54 Cf. RAHNER, H. Symbole der Kirche. Die Ekkesiologie der Väter, Salzburg, 272-273.

55 Cf. RAHNER, H. Griechische Mythen in christlicher Deutung. Zurique, 300-315.

56 Oktoichos ou Parakletike da Igreja católica ortodoxa do Oriente, de A. MALTZEN, 2a parte, 340s., Berlim, 1904, apud RAHNER, H. Symbole der Kirche, 356.

57 Cf. LAURENTIN, R. Court traité sur la Vierge Marie, Paris, 44.
} 
que foi sobretudo realidade religiosa, de união com o Salvador e de participação no seu destino salvífico. Maria nos salvou juntamente com o Cristo. Ela é, portanto, nesse sentido corredentora, cocriadora da nova criação, sem esquecer, é claro, que Maria, sendo também filha de Adão, precisou ser salva pelo Cristo. O Cristo, como princípio universal, salvou primeiramente a sua mãe, sem auxiliar, depois então tendo a ela como auxiliar, juntos salvaram o gênero humano. ${ }^{58}$

Não é por acaso que, no momento da primeira criação, o princípio feminino, personificado pela Sabedoria, tenha estado junto com o Deus criador, e que ao realizar a nova criação, pela redenção operada pelo Cristo, também um princípio feminino, representado pela pessoa de Maria, tenha estado igualmente presente. Tudo parece indicar, que ela é a nova personificação da Sabedoria. ${ }^{59}$

\section{Considerações finais}

Maria na teologia simbólica da patrística revelou a profundidade do pensamento dos autores desse período da Igreja, em que se viu a identidade entre Maria e a Igreja: a Igreja em Maria e Maria na Igreja, pois só se compreende o amor pelo mistério da Igreja-Mãe, a partir do grande amor que havia pela mãe terrestre do Salvador. No pensamento dos Padres, Cristo, o Filho de Maria, é o sol da justiça e da salvação. E Maria como a aurora da Nova Aliança, anuncia o Cristo, o sol da justiça, e sendo a aurora da salvação, a luz desse mesmo sol aparece refletido nela na claridade da aurora. Esse foi

58 O VATICANO II evitou usar o termo "co-redentora" e "co-redenção", por razões de caráter pastoral e ecumênico. Cf. MEO, S., Nuova Eva, in Nuovo Dizionario di Mariologia (NDM), 1985, 1022. É possível, no entanto, situar a aplicação do termo em seu verdadeiro contexto, a saber, o de Maria, a pobre de Javé, totalmente dócil e dependente dele, em comunhão com o destino de seu Filho até ao pé da cruz, momento central da redenção, sem fazer imprecações diante do seu Filho crucificado, mas se associando a ele como co-responsável e co-redentora. Cf. GOFFI, T., Spiritualità, in NDM, 1366-1367 
alguns dos aspectos que revelaram a rica simbólica da patrística sobre Maria.

\section{Bibliografia}

ALDAMA, J. A. Maria en la Patrística de los siglos I y II. Madri, 1970.

ARANDA, Antonio (ed.). Maria, camino de retorno. Nueva evangelización y piedad mariana. Pamplona: Ediciones Universidad de Navarra, S. A., 2012.

BASTERO DE ELEIZALDE, Juan Luis. María, Madre del Redentor. $3^{\text {a }}$ ed. Pamplona: Ediciones Universidad de Navarra, S. A., 2009.

BEINERT, Wolfgang (Ed.), Texte zur Theologie - Dogmatik vol. 6: Mariologie, seleção de textos por Franz Courth, Verlag Styria. Graz Wien Köln, 1991.

BÖGLER, Th. (Org.): Maria in Liturgie und Lehrwort, Maria Laach, 1954.

DEISSLER, G. A., Dann wirst du Gott erkennen. Die Grundbotschaft der Propheten, Freiburg im Breisgau, 1987.

DE FIORES, S.; MEO, S. (Org.). Nuovo Dizionario di Mariologia. (NDM) Roma: Paulinas, 1985.

DENZINGER, H.; SCHÖNMETZER, A. (DS). Enchiridion Symbolorum, Definitionum et Declarationum de Rebus Fidei et Morum.36 ed. Freiburg im Breisgau, 1976.

DÖLGER, Franz Josef. Die Sonne der Gerechtigkeit und der Schawarze, Münster 1979.

DÖLGER, Franz Josef. Sol Salutis, Münster, 1972

FORLAI, Giuseppe. Mãe dos Apóstolos. Viver Maria para anunciar Cristo. São Paulo: Paulus, 2015.

GAUDIO, Daniela Del. Maria de Nazaré. Breve tratado de mariologia. São Paulo: Paulus, 2016.

JOÃO PAULO II. Carta apostólica Mulieris Dignitatem (MD) de 15/08/1988. São Paulo: Paulinas, 1988.

JUNG, Carl Gustav. Gesammelte Werke (GW) (Obras Completas), 24 vol., Walter Verlag, Olten und Freiburg in Breisgau. 
JUNG, Carl Gustav. Psychologische Typen. Olten und Freiburg: Walter Verlag, 1981.

JUNG, Carl Gustav. Symbole der Wandlung. Olten und Freiburg: Walter Verlag, 1981.

DE FIORES, S.; MEO, S. (org.). Nuovo Dizionario di Mariologia. (NDM). Roma: Edizioni Paolini, 1985.

GAUDIO, Daniela Del. Maria de Nazaré. Breve tratado de mariologia. São Paulo: Paulus, 2016

JACOBI, J. Die Psychologie von C.G.Jung. Eine Einführung in das Gesamtwerk. Frankfurt a. M., 1982.

KASSEL, M., "Weibliche Aspekte im lukanischen Kindheitsevangelium”, in Diakonia, nov. 1984.

LAURENTIN, René. Court traité sur la Vierge Marie. Paris, 1967.

LAURENTIN, René. Marie Mère du Seigneur. Les beaux textes de deux millénaires, Paris : Desclée, 1984.

LIBANIO, João Batista; MURAD, Afonso. Introdução à Teologia. Perfil, Enfoques, Tarefas. $8^{\text {a }}$ ed. São Paulo: Loyola, 2011.

LUMEN GENTIUM. Documentos do Concílio Ecumênico do Vaticano II (1962-1965). São Paulo: Paulus, 2001.

MÜLLER, Alois. Ecclesia - Maria. Die Einheit Marias und der Kirche. Freiburg/CH, 1955.

PAPA FRANCISCO. Evangelii Gaudium (EG). A Alegria do Evangelho. Sobre o anúncio do Evangelho no mundo atual. Brasília: Edições CNBB, 2013.

PATROLOGIA GRAECA (PG), dir. por J.P.Migne. Paris, 1857-1866.

PATROLOGIA LATINA (PL), dir. por J.P.Migne. Paris, 1841-1864.

PAULO VI. Exortação Apostólica Marialis Cultus de 2 de fevereiro de 1974, in: AAS 66 (1974) 113-168. Trad. Brasileira: Vozes, Petrópolis.

PERRY, Tim; KENDALL, Daniel, SJ. A Santíssima Virgem Maria. São Paulo: Loyola, 2015.

POZO, Candido. María en la obra de la salvación. Madri, 1974.

RAHNER, Hugo. Symbole der Kirche. Die Ekkesiologie der Väter, Salzburg, 1964 
RAHNER, Hugo. Griechische Mythen in christlicher Deutung, Zurique 1966.

RAHNER, Karl. Schriften zur Theologie VI. Neue Schriften. Einsiedeln-Zürich-Köln, 1965.

RATZINGER, Joseph (Bento XVI). A Filha de Sião. A Devoção Mariana na Igreja. São Paulo: Paulus, 2014.

SEMMELROTH, O. Marie, archétype de 1’Église. Paris, 1965.

UNIÃO MARISTA DO BRASIL - UMBRASIL. Maria no coração da Igreja. Múltiplos olhares sobre a Mariologia. São Paulo: União Marista do Brasil/Paulinas, 2011.

VON BALTHASAR, Hans Urs. Sponsa Verbi. Einsiedeln, 1960.

VON BALTHASAR, Hans Urs. Der dreifache Kranz. Das Heil der Welt im Mariengebet. $3^{\text {a }}$ ed. Einsiedeln, 1978.

UNTERSTE, H. Theologische Aspeckte der Tiefenpsychologie von C.G. Jung. Düsseldorf, 1977.

Recebido em: 23/04/2016

Aprovado em: 16/05/2016 